\title{
Territorios de la memoria desobediente de las animitas
}

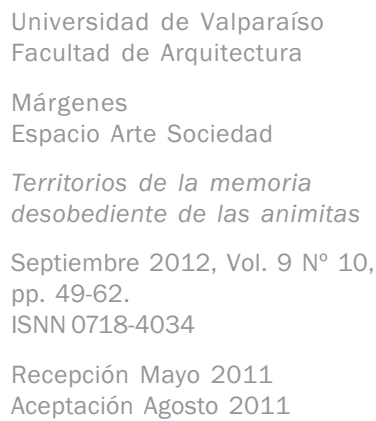

> Arquitecto Universidad de Valparaíso, 2005. Profesor Auxiliar Escuela de Arquitectura Universidad de Valparaíso. Doctor@ en Aménagement, Urbanisme et architecture. Université de Bretagne Occidentale, France, 2012

MIGUEL TORRES BRAVO

> Licenciado en Sociología Universidad de Chile, Magíster en Historia P.U.C.V.

\section{Resumen}

Esta investigación se sustenta en un catastro georeferencial, topológico y fotográfico de 219 animitas de la región de Valparaíso, centrándose en la conflictualidad dialéctica entre un patrimonio institucional y uno de carácter informal en la ciudad de Valparaíso. La presencia de un gran número de animitas en la zona de conservación histórica y en algunos casos adheridas a monumentos históricos revela y materializa esta confrontación entre memoria hegemónica y memoria desobediente o contra memoria. El artículo concluye con la definición de esta contra memoria como un patrimonio de interferencia que dibuja y desdibuja los espacios museificados por las políticas patrimoniales ${ }^{1}$.

Palabras claves

contra memoria, animitas, patrimonio urbano

\section{Territories of the animitas' disobedient memory}

\section{Abstract}

This research was based on a geo-referential, topologic and photographic land registry of 219 animitas in the Valparaíso Region, focusing in the dialectic conflict between an institutional and an informal heritage in the city of Valparaíso. The presence of a great number of animitas in the historic preservation area and in some cases, attached to historical monuments reveals and materializes this confrontation between the hegemonic and the disobedient or countermemory. The article ends with a definition of this countermemory as an interference heritage which draws and blurs the spaces turned into museums by the heritage policy.

\section{Key-words}

countermemory, animitas, urban heritage

\section{Territoires de la mémoire désobéissante des animitas}

\section{Résumé}

Cette recherche s'appuie sur une banque de données photographiques, un atlas géoréférencé et l'analyse topologique de 219 animitas de la région de Valparaíso, en abordant la conflictualité dialectique entre un patrimoine institutionnel et un patrimoine à caractère informel présent dans la ville de Valparaíso. La présence d'un grand nombre d'animitas dans la zone de conservation historique, dans quelques cas adhérés aux monuments historiques, révèle et matérialise la confrontation entre mémoire hégémonique et mémoire désobéissante ou contre mémoire. L'article conclut avec la définition de cette contre mémoire comme un patrimoine d'interférence qui dessine et efface les espaces muséifiées par les politiques patrimoniales.

\section{Mots Clefs}

contre mémoire, animitas, patrimoine urbain 


\section{¿CUÁL ES EL INTERÉS PARA ESTUDIAR LAS ANIMITAS?}

Primeramente, desde el punto de vista de la planificación urbana y la antropología urbana esta práctica se presenta como un paradigma arquitectónico, urbano, estético y social de las expresiones informales que poseen las ciudades contemporáneas y rurales de Chile, paradigma no menor si consideramos que la mayoría de los fenómenos urbanos de la ciudad contemporánea están en una constante dialéctica entre control y descontrol, entre formalidad e informalidad, entre planificación y espontaneidad. Segundo, el estudio serio de este tipo de práctica, permitiría no cometer errores por ignorancia, como lo fue el caso de las animitas estandarizadas de la autopista central, o la ingenua intervención urbana realizada por CONASET en el marco de la campaña "manéjate por la vida"2, pues en ambos casos solo se tomó en consideración el aspecto formal de las animitas, obviando la riqueza de su sentido ritual.

Al recorrer cualquier ciudad, pueblo y camino de Chile es inevitable encontrarse con una animita, y también es innegable que éstas están muy presentes en el acervo cultural de todo chileno, por lo cual la primera interrogante que surge cuando se estudian las animitas, refiere a su origen, ¿desde cuándo existen? ¿Y cómo han llegado hasta hoy día?

Hasta el momento existen dos hipótesis al respecto, la primera define las animitas como el producto sincrético de una herencia cultural ibérica que encuentra su antecesor en la devoción a las ánimas del purgatorio (Rojas, 2001), Cristian Parker (1992) señala que las animitas serían la versión chilena del culto a las ánimas, culto que proviene de la contrarreforma barroca y que dio luz a la noción del purgatorio, noción que en su implantación en América generó el culto a los muertos milagrosos. En Venezuela se conocen como las capillitas y las ánimas, en México como templos, capillas, en Perú como almitas, en Brasil como Capeliñas, y en Argentina como ermitas o nichos (Ojeda \& Torres, 2011).

Y la segunda hipótesis señala que éstas tendrían raíces Americanas y Europeas, pues en ambos continentes se tenía la costumbre de marcar ciertos sitios sagrados, los cuales eran testigos de múltiples ofrendas (Lira, 2002), y que al llegar la devoción de las ánimas al continente americano ya existían cultos similares que posibilitaron una rápida hibridación y adaptación, se trata entre otros del culto a los ancestros, expresados en las momificaciones artificiales (Arriaza, 2001), las Chullpas, las Apachetas, etc.

Para el desarrollo de esta investigación nos adherimos a la segunda hipótesis, que define las animitas como una manifestación prehispánica que influenciada por el cristianismo ha modificado su forma pero no su sentido.

En nuestros trabajos de terrenos en el norte grande de Chile y sur del Perú, hemos encontrado un sinfín de animitas $(2.457)^{3}$, muchas de las cuales se encontraban cerca de monumentos y centros ceremoniales prehispánicos. También encontramos Animitas con formas que hacen una referencia explícita a la cruz de la Chakana, y otras que se encontraban junto con apachetas y/o Chullpas, lo cual además de señalarnos un posible parentesco ritual, nos revela una ritualidad plural practicada por los habitantes de las zonas estudiadas, es decir una persona puede ser devoto de una Chulla al mismo tiempo que venera una almita o animita.
Ricardo Latcham en 1928, con respecto a las culturas andinas, señalaba que en muchos puntos, las formas y las ceremonias del ritual cristiano sirvieron para recubrir la continuación de su antigua devoción. Las imágenes y las figuras del nuevo culto reemplazaron a los ídolos destruidos, los cuales, en todos los casos, no eran otra cosa que las moradas temporales de espíritus que ellos adoraban y veneraban. Además los nuevos ritos fueron mirados favorablemente, considerados como la expresión de una magia más potente que la suya (Girault, 1988:2). Consideramos errada la idea que la cultura popular sea débil y que haya abandonado sus valores asumiendo los de la cultura dominante, y preferimos adscribirnos al modelo que plantea Cristian Parker (1996) en el cual los vencidos son vencedores, es decir de una cultura popular que ha resistido por siglos y asimilando de forma inteligente los cánones y patrones de dichas culturas dominantes. Por lo cual sostenemos que la práctica de las animitas a pesar de poseer una estética preeminentemente cristiana tiene un origen prehispánico.

Oreste Plath señalaba que Nace una 'animita' por misericordia del pueblo en el sitio en el que aconteció una 'mala muerte'. Es un cenotafio popular, los restos descansan en el cementerio, por lo que se honra el alma, la 'ánima'. (Plath, 1995:9). Es decir la animita es la expresión formal de empatía que el pueblo chileno posee hacia trágicas defunciones; la empatía ante la muerte trágica es una manifestación antropológicamente universal y sus expresiones formales pueden ser de las más variadas (Morin, 2003). Sin embargo el culto a las animitas no reconocido ni por el Estado ni por la Iglesia, es más bien tolerado como lo señalaría Ricardo Salas Astrain (1992), el punto es -al tratarse de una memoria colectiva viva que posee un vehículo formal de expresión (la animita como objeto) - saber hasta qué punto es tolerado y hasta qué punto este culto al ser revelado y/o reconocido puede ser desviado y/o controlado.

Es decir ¿son las animitas una memoria no-institucional que se adhiere y reconoce la memoria institucional? o ¿son una contra memoria que difiere de forma consciente o no a la memoria institucional, construyendo su propia historia?, son ¿unas memorias resistentes, alternas o ambas?

\section{MEMORIALIZACIÓN Y LAS ANIMITAS}

Uno de los valores de la animita como práctica y como objeto, desde la perspectiva del patrimonio, el urbanismo y la arquitectura, es poner en crisis varias prácticas institucionalizadas, normadas y estandarizadas. A continuación presentaremos cómo la animita pone en crisis la noción moderna del patrimonio y de paso las construcciones identitarias asociadas a la memoria colectiva de la nación. En anteriores publicaciones hemos definido el carácter polivalente y polisémico de la animita, defiriéndola como hologramas de la muerte imprevista (Ojeda \& Torres, 2011, Ojeda, 2011), creando un modelo sustentado en tres interpretaciones de la animita, como objeto holográfico ${ }^{4}$, como sujeto holográfico ${ }^{5}$ y como lugar holográfico ${ }^{6}$, es importante considerar estos tres aspectos pues es su constante imbricación la que le otorga pleno sentido, significado y forma a esta práctica y por consecuencia en su consolidación en tanto que memoria colectiva. Alicia Lindón señala que la tradición sociofenomenológica establece que la construcción de los significados se realiza desde los acervos 
de conocimiento y de sentido común objetivados en el lenguaje [...]. Sin embargo, Berger y Luckmann especifican el tema, mostrando que dicha construcción se alimenta de tres núcleos principales que hacen a la subjetividad del individuo. Estos son: la percepción, la imaginación y la memoria (2000, p. 199). Es decir en el modelo polivalente de análisis, la animita como objeto guarda relación con la percepción formal que los practicantes poseen de estas, la animita como sujeto guarda relación con el imaginario social desplegado en torno a la figura del difunto conmemorado, y la animita como lugar guarda relación con el traslape entre la animita como objeto y como sujeto, cristalizándolo en una memoria colectiva desde en un lugar y tiempo determinado.

Hoy la velocidad de la ciudad contemporánea, entre sus megaestructuras de desplazamiento y sus medios hipertextuales de comunicación, acentúa la necesidad colectiva de conservar el pasado, pues las múltiples posibilidades de poder actuar e interactuar en espacialidades y temporalidades desfasadas, dan la impresión de estar en varios sitios y momentos a la vez. Una sensación de ubicuidad y multitemporalidad acompaña al doble proceso de 'deslocalización' y 'desinstantaneización' (Ascher, 2004: 35), por lo que el pasado se mezcla fácilmente con el presente y el futuro, lo cual debilita la noción moderna de la construcción de una memoria hegemónica, que reflejaba las intenciones y creencias de las autoridades y/o elites.

En lo que refiere la memoria hegemónica, François Ascher (2004) señala que la noción de patrimonio fue creada en la tercera fase de modernización de la ciudad europea, cuyo fin era conservar ciudades, vestigios, monumentos y elementos de valor artístico. Esta es una noción preeminentemente moderna; pues antes de ello las ciudades no reparaban si construir o no sobre sus vestigios y ruinas (Choay, 2006). Esta noción de patrimonio fue instaurada y establecida desde la institución, obviando la implicancia de la ciudadanía, lo que en muchos casos trajo consigo la cristalización de un pasado en un presente sin alma, fenómeno conocido como museificación (Lacarrieu, 2007), donde los espacios públicos pierden sus cualidades ciudadanas para convertirse en espacios viarios, o en áreas turísticas y de ocio o museificadas (Borja, 2011: 141). Andreas Huyssen (2002) define que esta noción patrimonial se ha convertido en una "obsesión" hacia la "cultura de la memoria" o en otras palabras un culto de/a la memoria asociado al riesgo de su propio 'abuso' (Lacarrieu, 2004:155)

En esta frenética conquista del pasado, se distinguen dos manifestaciones sociales complementarias y a veces contrapuestas: primero refiere a la memoria colectiva no institucional, que definimos como la confluencia de relatos, mitos, usos, representaciones, expresiones, conocimientos y técnicas transmitidas de manera informal, espontánea, paralela y no estandarizada, la cual conforma la identidad de un grupo social determinado, de escala variable y socialmente transfigurable, tendiendo a lo inclusivo, por ejemplo: en el caso de las animitas, todo aquel que ha muerto injustamente de forma violenta, puede transformarse en un santo popular.

En segundo lugar encontramos la memoria institucional, que a través de múltiples mecanismos y herramientas institucionalizadas, intenta normalizar y dictar las reglas y costumbres a seguir, determinando qué es lo que se puede recordar y lo que no (Lacarrieu, 2004). Esta memoria tiende a la exclusividad, por ejemplo: según los cánones de la Iglesia Católica, no cualquiera puede ser proclamado como santo. La memoria institucional se acerca a la noción de patrimonio institucionalizado. En Chile la noción de patrimonio se hizo explícita a partir de 1925 con la creación del consejo de monumentos nacionales a través del Decreto Ley No 651 (Ayala Rocabado, 2008:40), dicha institucionalización se sustentó con la intención de crear una identidad nacional única y absoluta donde no existieran conflictos ni contradicciones, pero la tendencia fue la homogeneización y normalización de una identidad plural y compleja (López, 2004:187). En ese entonces sólo se reconocían iglesias, fuertes y edificios públicos de cánones occidentales (europeos) (Ayala Rocabado, 2008). No se puede negar que la idea de 'patrimonio mundial' y la creación de un movimiento internacional para la protección de sitios culturales y naturales [...] son desde sus orígenes, una imposición de valores occidentales (Curtoni \& Chaparro, 2007: 14). De esta manera se generó una evidente distancia entre los diferentes grupos étnicos y socio-económicos, donde la elite chilena, avalada por el Estado, reconocía y valoraba los componentes materiales de su identidad y desacreditaba los componentes materiales e inmateriales provenientes de las clases inferiores $y / o$ de los pueblos originarios ${ }^{7}$.

El problema es que estas nociones han construido una historia y una memoria con una connotación de verdad absoluta e inapelable, donde el monumento histórico producido y reproducido por la elite chilena, se encargó de sellar con cierta opulencia apelando a una herencia docta proveniente del mundo occidental. Bajo estas formas eurocéntricas de producción y reproducción del conocimiento se anulan, silencian y/o niegan, por medio de diferentes estrategias, las posibilidades de existencia de "otras" alternativas de construcción y circulación de los saberes (Curtoni \& Chaparro, 2007:13). En Chile esto se puede apreciar en la lista de monumentos históricos del consejo de monumentos, específicamente en la categoría de casas de personajes ilustres de la sociedad chilena, que entre 1925 y 2012 se eleva a 157 bienes en la categoría de "casas", de los cuales 149 están asociadas a personajes de la elite chilena y sólo $8^{8}$ asociados a personajes que tuvieron una abierta vinculación con el mundo popular, como lo fueron Gabriela Mistral, Pablo Neruda y Violeta Parra.

Françoise Choay (2009) aclara que este fenómeno de elitismo patrimonial se debe en parte a que el monumento histórico no es una creación ex nihilo construida con fines memoriales y que no se asocia a la memoria viva de un colectivo social. El monumento histórico es una edificación elegida en un corpus de edificios preexistente por sus valores históricos y/o estéticos, los cuales lógicamente son determinados por el Estado y sus organizaciones. Lo interesante es la diferenciación entre monumento histórico y monumento, donde la primera corresponde a una memoria determinada por ciertos cánones elitistas y la segunda es la resultante de una creación colectiva para fines memoriales y/o rituales, Marc Augé (1992) señala que el monumento se asocia a una voluntad tangible de la permanencia en el tiempo y que sin ilusión monumental, a los ojos de los vivos, la historia no sería sino una abstracción (78) aludiendo que el espacio social está conformado por una serie de monumentos imponentes o modestos que generan en 
los individuos un sentimiento de pertenencia asociado a la perennidad de estos monumentos. Paralelamente Françoise Choay plantea la siguiente definición para el monumento:

Para definir el término "monumento", se referirá a su etimología. Este deriva del sustantivo latino monumentum, el cual es resultante del verbo monere: "informar", "recordar a la memoria". Se llamará entonces "monumento" a todo artefacto (tumba, estatua, poste, tótem, edificio, inscripción...) o conjuntos de artefactos deliberadamente concebidos y realizados por una comunidad humana, cualquiera que sean su naturaleza y dimensiones (de la familia a la nación, del clan a la tribu, de la comunidad de creyentes a la de la ciudad...), con el fin de recordar a la memoria viva, orgánica y emocional de sus miembros, de las personas, de los acontecimientos, de las creencias, de los ritos $y / 0$ convenciones sociales constitutivas de su identidad. El monumento se caracteriza asi por su función identificatoria. Por su materialidad, redobla la función simbólica del lenguaje cuya volatilidad atenúa. (Choay, 2009: V).

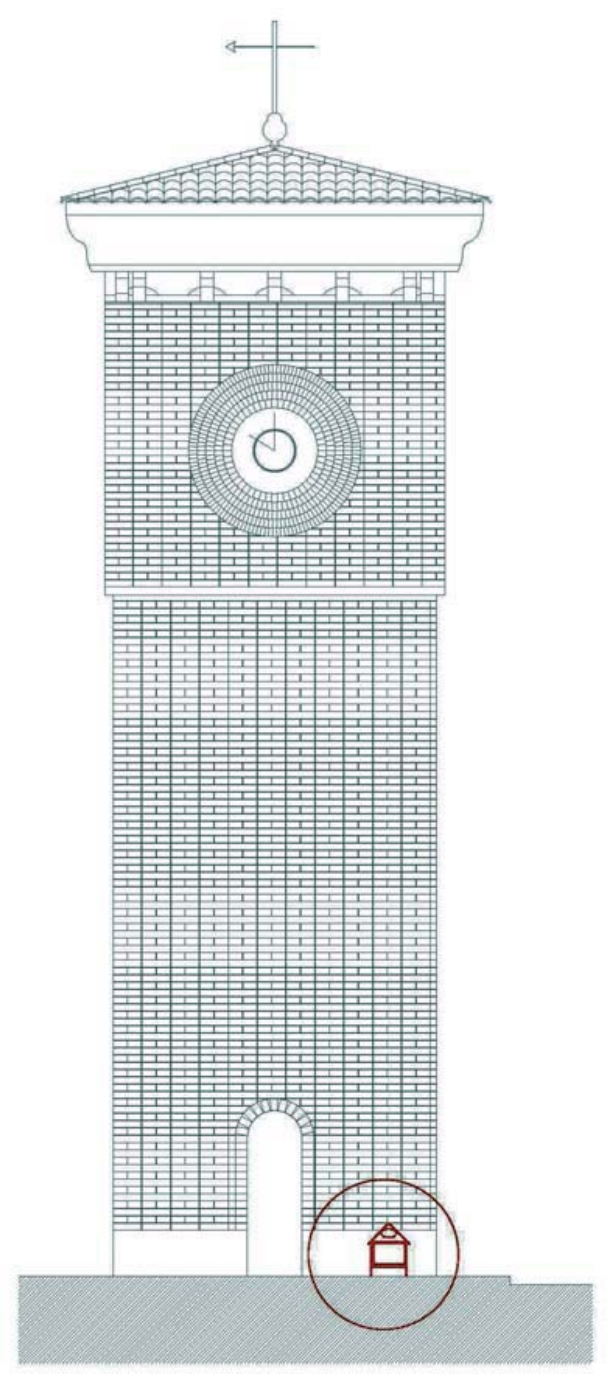

Figura 1 Planimetría de Torre Reloj Barón y animita de Rigoberto Mura, Fuente: Lautaro Ojeda, Proyecto Fondart 19189-2
Estas definiciones permiten una conclusión simple pero necesaria de explicitar para el caso de las animitas, y refiere a que toda construcción y/o sitio, lo que incluye los monumentos, pueden convertirse en monumentos históricos, sin embargo no todo monumento histórico puede tener la condición y aceptación social del monumento. Es decir las animitas como objeto (cenotafio o sepulcro vacío), gracias a su génesis espontánea y mantención por parte de un cuerpo social determinado, son indudablemente monumentos y si bien ninguna posee la designación de monumento histórico, ello no afecta su reconocimiento ni tampoco su perdurabilidad; en cambio un monumento histórico que es designado por sus cualidades históricas y/o estéticas no necesariamente contará con el reconocimiento y mantención por parte del cuerpo social que habita el espacio de su emplazamiento. Es decir esta dialéctica entre monumento y monumento histórico revela un conflicto mayor, que es el de la apropiación y cualificación del espacio, y más precisamente del espacio público, pues es muy recurrente el caso de monumentos históricos que no tienen un reconocimiento social y que su espacio y entorno edificado se conviertan en un área turística museificada y/o gentrificada (Borja, 2011), y por otra parte el monumento que si cuenta con una aceptación ciudadana amplia, carece de credibilidad ante las autoridades por su carácter popular y/o populista, y porque no decirlo por su bajo valor "turístico". Lacarrieu señala que la ciudadanía, ya sea de forma explícita o tácita, se involucra directamente en esta disputa asociándose por defecto a complejos procesos de memorización o construcción y/o consolidación continua en el tiempo de una memoria colectiva antes de involucrarse en procesos de patrimonialización. Entre ambos caminos se intersecta la ambigüedad dada por una visión naturalizada, que automáticamente muestra y coloca al patrimonio como un bien museístico intocable e incontaminable de todo aquello que parece "feo, sucio y malo (Lacarrieu, 2004:179). En nuestros trabajos de terreno en la ciudad Valparaíso, incluida en la lista de patrimonio mundial de la UNESCO desde 2003, en reiteradas ocasiones los ciudadanos nos han manifestado su malestar con respecto a la designación patrimonial de la ciudad, aludiendo que ellos también son el patrimonio y no solo un sector determinado de la ciudad $^{9}$, es decir gran parte de la población se siente excluida de este reconocimiento y sus aportes. En este sentido, la "ausencia de gente" con que se vincula al patrimonio, se ecuaciona directamente con la "presencia de gente" en la recuperación y constitución de la memoria. La memoria no institucionalizada permite volverla parte del campo de "lo popular", plena de "espontaneidad", cargada del sentido de recuperación del pasado para dar significación al presente (Lacarrieu, 2004:162).

En 1996, la UNESCO publicó una lista de patrimonio mundial que reveló un desequilibrio en los criterios de selección de los bienes de valor universal excepcional, pues en ella prevalecían los centros históricos (29\%), los monumentos y catedrales cristianas (20\%) y los palacios y castillos (6\%), ubicados en su mayoría en Europa (48\%) (Curtoni \& Chaparro, 2007: 15), de los cuales Chile no presentaba ningún bien inscrito ${ }^{10}$. Si bien hoy se está intentando revertir este desbalance, las estadísticas siguen favoreciendo al continente europeo con un $48 \%$ de bienes inscritos. 
Paralelamente en Chile, el Consejo de Monumentos Nacionales, desde 1925 hasta la fecha, ha declarado 1.288 monumentos nacionales, de los cuales el $87.9 \%$ corresponde a Monumentos históricos, $8.9 \%$ a zonas típicas y 3.2\% a Santuario de la Naturaleza ${ }^{11}$, de los 1.132 monumentos históricos el 55.5\% corresponde a monumentos y edificios religiosos, de los cuales un $27.8 \%$ corresponde a edificios exclusivamente religiosos, un $5.9 \%$ a edificaciones militares $\mathrm{y} / \mathrm{o}$ de defensa, y un $66.3 \%$ a edificios de carácter público. Paralelamente de los 1.288 monumentos nacionales (1925-2012) un $8.9 \%$ corresponde a centros históricos, un $48.75 \%$ a Monumentos y edificios religiosos, un $2.4 \%$ a palacios y castillos, un $2.87 \%$ a sitios arqueológicos y un $0.7 \%$ a pueblos originarios. Estas cifras muestran una realidad inversa a la mundial en cuanto el Estado reconoce más monumentos históricos que centros históricos, tendencia donde prima el reconocimiento por monumentos de carácter público y religiosos, revelando, entre otros, un bajo interés en el patrimonio que podría provenir de prácticas populares. Estos antecedentes de dislocación identitaria y la tendencia en reconocer un patrimonio proveniente de la elite chilena nos hacen cuestionar la validez del Estado y los organismos internacionales para definir y declarar lo que es patrimonio o no y la gestión del mismo (Lacarrieu, 2004; Curtoni \& Chaparro, 2007).

Estos conflictos no son nuevos, pues en 1991, la UNESCO, ante este tipo de conflictos que enfrentaban patrimonio material, los centros históricos y sus expresiones sociales, realizó los primeros reconocimientos a expresiones inmateriales y orales, denominándolas como patrimonio inmaterial (Bojalil, 2002). En 1992, se determinó que las zonas geográficas de alta interacción humana se incluirían en los criterios de Bien Universal de Valor Excepcional, y serían consideradas como paisajes culturales.

Estos antecedentes permitieron que la conferencia de Nara (Japón 1994) se centrara en la discusión acerca del valor de la autenticidad en la conservación y el manejo, concluyendo que "cada bien patrimonial se considere y juzgue dentro de los criterios del contexto cultural al que pertenecen" (Curtoni \& Chaparro, 2007: 15).

Los ámbitos que inicialmente definieron el patrimonio inmaterial, fueron tradiciones y expresiones orales; artes escénicas; prácticas sociales; y conocimiento y prácticas relativas a la naturaleza y al universo. Un último dominio, el de la lengua, fue incorporado después en la Convención (Arizpe, 2006: 24). Más adelante, en la Convención de 2003, se ampliarían y precisarían los ámbitos, que actualmente comprenden las tradiciones y expresiones orales, incluyendo el idioma como vehículo de transmisión; las artes del espectáculo; los usos sociales, rituales y actos festivos; los conocimientos y usos relacionados con la naturaleza y el universo; y finalmente las técnicas artesanales tradicionales (UNESCO, 2010).

La Convención para la Salvaguardia del Patrimonio Cultural Inmaterial, redactada en el año 2003, definió el patrimonio inmaterial de la siguiente manera:

Artículo 2. definiciones: 1. Se entiende por "patrimonio cultural inmaterial" los usos, representaciones, expresiones, conocimientos y técnicas -junto con los instrumentos, objetos, artefactos y espacios culturales que les son inherentes-que las comunidades, los grupos y en algunos casos los individuos reconozcan como parte integrante de su patrimonio cultural. Este patrimonio cultural inmaterial, que se transmite de generación en generación, es recreado constantemente por las comunidades y grupos en función de su entorno, su interacción con la naturaleza y su historia, infundiéndoles un sentimiento de identidad y continuidad y contribuyendo así a promover el respeto de la diversidad cultural y la creatividad humana. (UNESCO, 2010: 5)

Esta definición expresa claramente que los objetos, artefactos y espacios culturales son inherentes a lo intangible, dejando entender que a toda expresión tangible se le adhiere una expresión intangible, sin embargo, en el campo institucional permanece y prevalece una visión que define al patrimonio en relación a "cosas" u "objetos" descontextualizados del entorno sociocultural en que se producen y desde el cual obtienen eficacia simbólica (Lacarrieu, 2004: 157). Este patrimonio inmaterial se transmite de generación en generación reconstruyendo su forma social y funcional en función de su entorno. El patrimonio inmaterial puede ser entendido desde muchas perspectivas, pero en el centro de todas estas, están las prácticas y creencias que definen la identidad cultural, la diversidad cultural y la creatividad humana de cada pueblo (UNESCO, 2010).

Si consideramos que el patrimonio inmaterial de una cultura se sustenta en las costumbres, tradiciones, creencias, mitos, lenguajes y prácticas sociales, podemos asociar este patrimonio a la identidad cultural de un grupo social determinado, y reconocer, en suma, que el vínculo entre unos y otros es íntimo hasta el punto de que puede concebirse tal patrimonio inmaterial [...] como basamento conformador de una identidad cultural. (Massó Guijarro, 2006: 92).

La práctica de las animitas, cumple con creces estos criterios establecidos por la convención de la UNESCO; Pues son instrumentos memoriales intencionales cargados de afecciones y simbolismos, que canalizan múltiples funciones y manifestaciones sociales, construyen un paisaje cultural de carácter ritual y mortuorio. Sin embargo la riqueza de las animitas (entendidas como monumentos memoriales conmemorativos), reside en su doble condición material e inmaterial. Los relatos, mitos, historias y creencias constituyen un bien inmaterial no cuantificable, y la construcción de templetes, delimitaciones topológicas, disposición de ofrendas, exvotos y placas de agradecimiento constituye un bien material orgánico.

Es así que en esta práctica, inmaterialidad y materialidad son un todo indisociable, por lo que para su resguardo y valorización se hace necesaria una mirada pluridisciplinaria que implemente múltiples herramientas complementarias, donde un registro antropo-arquitectónico y una clasificación científica son indispensables para construir un discurso de reivindicación patrimonial local, tanto material como inmaterial. Del conjunto de todas aquellas disciplinas profesionales que confluyen e inciden en la construcción social del paisaje, quizás es la arquitectura una de las que más énfasis pone en la visibilidad de la estructura de ese paisaje. (Itziar González Virós, 2007: 163), ¿pero es posible gestionar un patrimonio que tiene una génesis y una dinámica informal y espontánea? ¿Es adecuado reconocer y valorar desde una mirada 
academicista y/o elitista una práctica popular que se ha auto valorado y gestionado por más años que la propia nación?, creemos pertinente el reconocimiento valórico, pero no creemos pertinente una regulación y gestión por parte del Estado y/o cualquier institución, creemos que el estado podría actuar como observador y veedor en los casos en los cuales se presenten conflictos de intereses que impliquen posibles destrucciones que atenten contra este patrimonio cultural.

Retomando los aspectos legales del patrimonio, el artículo 13d de la Convención del 2003, estipula que todos los estados partes, para lograr promover, consolidar y preservar su patrimonio intangible, deben establecer medidas en el orden jurídico, técnico y administrativo:

(d) Adoptar las medidas de orden jurídico, técnico, administrativo y financiero adecuadas para:

(i) Favorecer la creación o el fortalecimiento de instituciones de formación en gestión del patrimonio cultural inmaterial, así como la transmisión de este patrimonio en los foros y espacios destinados a su manifestación y expresión;

(ii) Garantizar el acceso al patrimonio cultural inmaterial, respetando al mismo tiempo los usos consuetudinarios por los que se rige el acceso a determinados aspectos de dicho patrimonio;

(iii) Crear instituciones de documentación sobre el patrimonio cultural inmaterial y facilitar el acceso a ellas (UNESCO, 2010, pp. 9-10).

Todas estas garantías y mecanismos deben tener una fuente de financiamiento inagotable, y los estados, en un mundo económico cada vez más incierto, solo pueden establecer criterios de rentabilidad patrimonial. Esta es una de las razones por las que el discurso patrimonial impulsado por la UNESCO, ICOMOS y los estados asociados, centra sus políticas en la rentabilidad del patrimonio material e inmaterial (Bialogorski \& Fischman, 2002; Ayala Rocabado, 2008), por ello no resulta extraño que la fiesta de la tirana cuyo pueblo fuera incluido como monumento en calidad de Zona Típica en 1971, se haya desdibujado hasta perder su esencia (Guerrero, 2011), o la violenta gentrificación del casco histórico de Valparaíso. El interés social en la noción de patrimonio es real, pero la generalización y estandarización de lo que es o no es patrimonio se debe a la confluencia entre los medios de comunicación, el marketing, la influencia de organismos como UNESCO e ICOMOS, y el incremento de los desplazamientos de los turistas, contribuyendo de esta forma, al consumo masivo de "memorias y patrimonios comercializables”. (Lacarrieu, 2004: 155). Estos criterios de rentabilidad, excluyen por defecto todo tipo de manifestación de carácter informal y toda forma económica informal auto-gestionada.

Mónica Lacarrieu señala que UNESCO en 1997 declaró que lo tangible sólo es interpretado mediante lo intangible, sin embargo, en el campo institucional permanece y prevalece una visión que define al patrimonio en relación a "cosas" u "objetos" descontextualizados del entorno sociocultural en que se producen y desde el cual obtienen eficacia simbólica (Lacarrieu, 2004:157). Es bajo esta óptica que el Estado y sus organismos se han encargado de delinear las legitimaciones, de lo que debe patrimonializarse y qué no (Lacarrieu, 2004:159). Lacarrieu plantea que las políticas patrimoniales estatales, han eludido la no- ción de memoria (colectiva o individual), y que esta visión eludiría de forma explícita la natural confrontación entre "memorias hegemónicas” y “memorias disidentes” (Lacarrieu, 2004:162).

\section{¿MEMORIA RESISTENTE O ALTERNA?}

Las animitas como práctica y como objetos simbólicos, han permitido y posibilitado la construcción de una memoria al margen de la memoria oficial y/o docta por más de doscientos años; esta longevidad de las animitas como memoria popular y espontánea pone en crisis la validez de la obsesión contemporánea por la construcción y preservación de una memoria artificial erigida por el Estado, que deriva a una obsesión por promocionar el consumo masivo de "memorias y patrimonios comercializables (Lacarrieu, 2004:155). Para el Estado y otras instituciones involucradas, el problema que suscitan las prácticas populares de carácter espontáneo, tiene una doble raíz, la primera radica en reconocer valores que podrían ir en contra de prácticas y políticas estatales, como lo es el caso de las animitas de los fusilados ${ }^{12}$ o en el caso de los detenidos desaparecidos del periodo de la dictadura militar (1973-1990) $)^{13}$, y segundo sobre cómo intervenir y regular una práctica social inminentemente inmaterial evitando su esterilización y congelamiento. Paralelamente para la Iglesia este tipo de prácticas también presentan un problema y que radicaría en reconocer una práctica calificada de pagana, inculta, desviada y supersticiosa, que se esmera en reconocer personajes que van en contra de los credos de la Iglesia Católica (Parker, 1996; Losonczy, 2001). Resulta evidente que la práctica de las animitas es plural, y mezcla laicismo con catolicismo sin mayores inconvenientes, así como se sustenta en su doble condición material e inmaterial, lo cual conlleva a que sus bienes simbólicos, sus objetos devocionales y sus creencias se vuelvan intercambiables y permeables entre ellos (Losonczy, 2001), permeabilidad que supera con creces la dicotomía academicista y/o legista entre material e inmaterial, entre oficial y no oficial, entre laicismo y cristianismo. Es decir puede entenderse las animitas como una práctica secular revestida de creencias religiosas o inversamente, puede entenderse las animitas como una práctica religiosa de carácter secular.

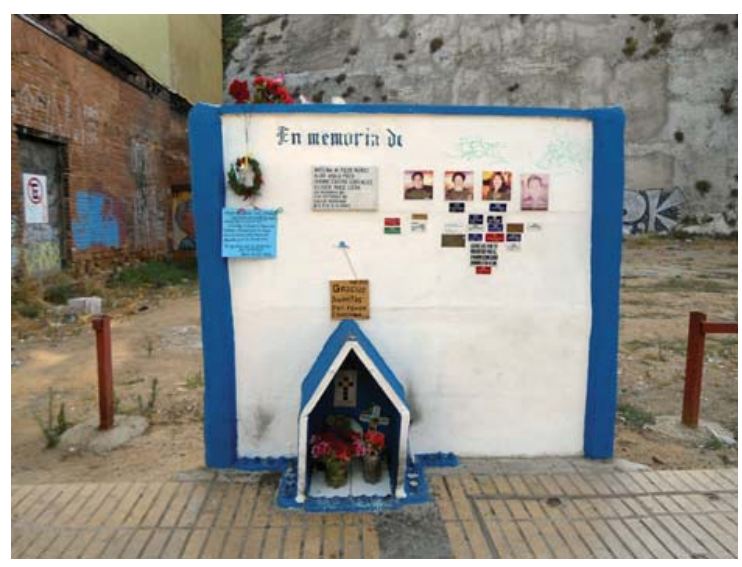

Figura 2 Fotografía de animita de Avelina Pozo en sector puerto. Fuente: Lautaro Ojeda, Proyecto Fondart Animitas en el camino 2011 


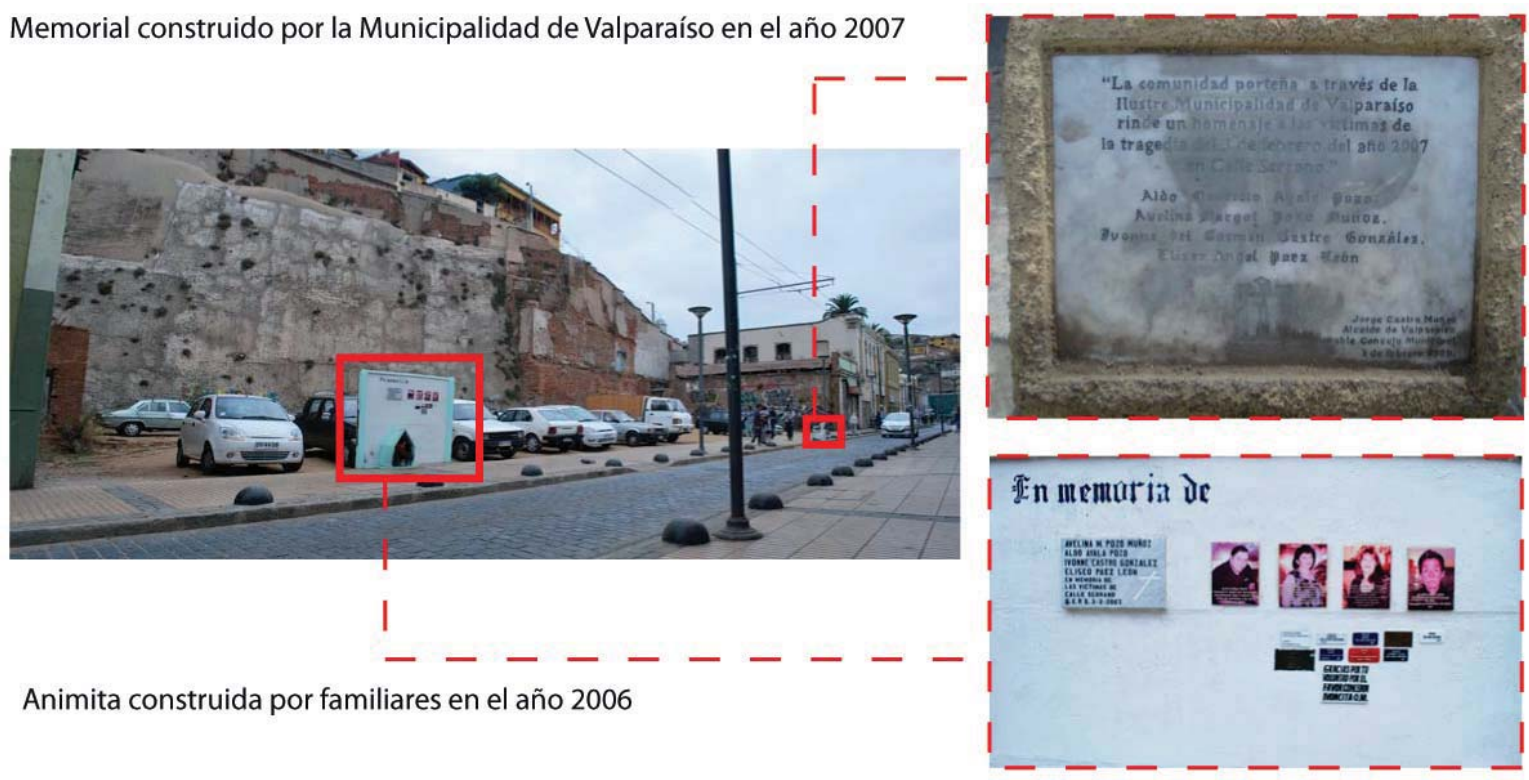

Figura 3 Fotografía de memorial construido por la I. Municipalidad de Valparaíso para Avelina Pozo en sector puerto. Fuente: Lautaro Ojeda, Proyecto Fondart Animitas en el camino 2011

Es considerando los antecedentes socio-políticos de la construcción y conservación de los elementos materiales e inmateriales que el Estado ha definido como conformador de la nación que definimos la práctica de las animitas como una memoria disidente o como lo que Anne-Marie Losonczy ha definido como una "Contra-memoria colectiva" (2001: 18), puesto que Resulta iluminador pensar en la memoria como un lugar menos institucionalizado, o en ausencia de institucionalidad, mientras el patrimonio propiamente tal vendría a ser el lugar de lo institucional (López, 2004:186). La contra-memoria colectiva tiende a lo emocional; por contraparte, la memoria institucional tiende a la racionalidad, y la superposición de ambas memorias conforma una conocimiento inmaterial que posee múltiples expresiones y prácticas, entre las cuales distinguimos la práctica de las animitas.

\section{PATRIMONIO URBANO DE INTERFERENCIA DE LAS ANIMITAS}

La práctica de las animitas no anula el patrimonio institucional, es más, en muchos casos lo asume y lo incluye. Jordi Borja señala que La ciudad será tanto más incluyente cuanto más significante. La ciudad "lacónica", sin atributos, sin monumentalidad, sin lugares de representación de la sociedad a sí misma, es decir, sin espacios de expresión popular colectiva, tiende a la anomia y favorece la exclusión (Borja, 2003: 28). Anteriormente nos hemos referido a la animita como monumento, recalcando sus valores inmateriales, confrontándola al monumento histórico, pero las animitas también entran en dialéctica con la ciudad histórica (Borja, 2003) ${ }^{14}$. Borja define la ciudad histórica como el conjunto de ciudades heredadas, es decir la ciudad histórica es la superposición de las ciudades romanas, medievales, barrocas, coloniales e industriales y en el caso latinoamericano debemos agregar la ciudad prehispánica. Esta noción de ciudad histórica es equivalente a la noción de patrimonio urbano histórico ${ }^{15}$ que Gustavo Giovannoni acuñara en
1933 (Choay, 1992), Choay explica que esta noción de patrimonio histórico se constituyó como contracorriente al proceso de urbanización dominante (1992:134), de la revolución industrial, representada por los ensanchamientos urbanos de Haussmann y Cerdá, y que tuvo tres fases representada por John Ruskin (1840), Camilo Sitte (1889) y Gustavo Giovannoni (1933). La primera fase representada por Ruskin en un contexto anglosajón, reivindicaba el valor de la arquitectura doméstica otorgándole el mismo valor que la arquitectura monumental, rechazando las destrucciones masiva que realizaban las nuevas operaciones urbanas de la revolución industrial (Choay \& Merlin, 2010). En oposición a la postura de Ruskin, Camilo Sitte estimaba que los antiguos tejidos urbanos eran una traba para el necesario desarrollo moderno, por lo cual con la finalidad de realizar nuevos proyectos modernos acordes a los antiguos espacios realizó una serie de minuciosos catastros, que paradójicamente serían el origen de la conservación museística de las ciudades históricas (Choay \& Merlin, 2010: 544). Choay explica que finalmente Giovannoni supera ambas posturas antagónicas, pues sustituyó el concepto de arquitectura doméstica, por uno más general, el de arquitectura menor, hace de la ciudad histórica un monumento en sí, e irreducible a la suma de sus partes, y sobre todo elabora una teoría que reintroduce los antiguos tejidos a la vida contemporánea integrándolos en los nuevos planes directores de urbanismo (Choay \& Merlin, 2010: 544). Además de ello Giovannoni introdujo el valor social del patrimonio urbano (Choay, 1992), valor que en nuestro caso comprendemos como las prácticas populares desplegadas en el espacio público, que en algunos casos es considerado como espacio patrimonial.

La Ley General de Urbanismo y Construcción, con el fin de regular las zonas que puedan presentar un valor histórico, señala lo siguiente en su artículo $N^{\circ} 60$ :

Artículo 60: El Plan Regulador señalará los terrenos que por su especial naturaleza y ubicación no sean edificables. 
Estos terrenos no podrán subdividirse y sólo se aceptará en ellos la ubicación de actividades transitorias, manteniéndose las características rústicas del predio. Entre ellos se incluirán, cuando corresponda, las áreas de restricción de los aeropuertos.

Igualmente, el Plan Regulador señalará los inmuebles o zonas de conservación histórica, en cuyo caso los edificios existentes no podrán ser demolidos o refaccionados sin previa autorización de la Secretaría Regional de Vivienda y Urbanismo correspondiente (L.G.U.C, 2010: sp).

$\mathrm{Y}$ por su parte el MINVU define que los inmuebles y las zonas de conservación históricas se encuentran bajo el mismo concepto de patrimonio urbano, definiendo este último de la siguiente forma:

El patrimonio urbano comprende las edificaciones y los espacios públicos cuya forma constitutiva es expresión de la memoria colectiva, arraigada y trasmitida, los que en forma individual o en conjunto, revelan características culturales, ambientales y sociales que expresan y fomentan la cultura y el arraigo social. (MINVU, 2012: s.p)

Es con esta visión que el Consejo de Monumentos Nacionales desde 1971 ha declarado 109 zonas típicas a lo largo de todo Chile, de las cuales 11 se encuentran en la ciudad de Valparaíso ${ }^{16}$. Para ello el Consejo de Monumentos clasificó las zonas típicas en cinco categorías: 1. Aéreas urbanas, 2. Centros históricos, 3. Conjuntos Residenciales, 4. Entorno a Monumentos Históricos, 5. Pueblos tradicionales. Y en Valparaíso se declararon 9 áreas urbanas y 2 entornos a monumentos históricos. De las nueves áreas urbanas declaradas como zonas típicas cinco se encuentran en el plan de la ciudad, dos corresponden a cerros de la ciudad y el noveno constituye el área histórica ${ }^{17}$ que en el año 2003 la UNESCO incluyera en la lista del patrimonio mundial ${ }^{18}$ y conformada por la sumatoria de seis de estas áreas urbanas. El expediente de postulación para la inscripción de Valparaíso a la lista del patrimonio mundial de la Unesco realizado por la Municipalidad de Valparaíso reconoce y valora las expresiones populares calificándolas de "vernáculas", sin embargo no profundiza mayormente sobre éstas, y define Valparaíso como una ciudad americana original, que se configura hacia la segunda mitad del siglo XIX, bajo parámetros en buena medida centroeuropeos (Cuadernos del Consejo de Monumentos Nacionales, 2003: 30), definición que en buena medida sublima la realidad vernácula de la ciudad, que desde sus inicios ha sido testigo de un equilibrio entre casas patronales y viviendas precarias, es decir este informe muestra solo una parte de la realidad haciendo hincapié en la herencia centroeuropea presente en algunos sectores de la ciudad, esta valoración implicó que el área urbana inscrita en el área histórica que ha presentado mayor desarrollo, y mayor valoración corresponde al Sector de los Cerros Alegre y Concepción, dos cerros que el expediente define como: un sector unitario, urbanizado y construido en gran parte por inmigrantes ingleses y alemanes, a partir de la primera mitad del siglo XIX, de manera organizada y planificada (Cuadernos del Consejo de Monumentos Nacionales, 2003: 46), esta visión de Valparaíso tiene una clara tendencia elitista sobre lo que se valora y lo que no. Finalmente cabe señalar que este sector de la ciudad desde hace dos décadas ha sufrido una museificación, que se ha traducido en una alza exorbitante de los valores de los bienes raíces, en una explosión de apertura de tiendas de lujo, de boutiques de lujo, de restaurantes de lujo, hoteles de lujo y albergues para turistas, todos los cuales en su conjunto han producido una gentrificación de estos dos cerros, desconectándose de la realidad socio-espacial del resto de la ciudad, si bien este proceso se ha dado por las libertades que otorga el modelo neoliberal chileno, las instituciones implicadas en el desarrollo de la ciudad Valparaíso como patrimonio universal ${ }^{19}$ no le han puesto un freno, pues estas debiesen haber velado para encontrar un equilibrio social que mantuviera el carácter histórico de Valparaíso.

Reconocemos el valor de la declaración patrimonial de Valparaíso, sin embargo creemos que para desarrollar una visión integral de la ciudad, hace falta un reconocimiento de las prácticas informales presentes en todos los sectores de la ciudad que hasta hoy se han declarado como componentes de la zona de conservación histórica, pues creemos que son estas prácticas las que le otorgan sentido al presente de la ciudad, las que le entregan memoria, pues La ciudad es pasado apropiado por el presente y es la utopía como proyecto actual. Y es el espacio suma de tiempos. Así como no hay comunidad sin memoria, tampoco hay ciudad sin proyecto de futuro. Sin memoria y sin futuro la ciudad es un fantasma y una decadencia (Borja, 2003: 27). Desde esta perspectiva las animitas se inscriben en un universo de prácticas urbanas adheridas al espacio público patrimonial que lo redibujan, reestructuran y organizan de forma incesante, modificándolo de manera orgánica, y es lo que hemos definido como patrimonio urbano de interferencia sustentado en la definición de "paisaje de interferencia” 20 realizada por Raquel Tardin-Cohelo (2007).

El caso del patrimonio urbano de interferencia de las animitas situadas en el área histórica y la zona de conservación histórica de la ciudad de Valparaíso no es menor y devela un enfrentamiento entre un patrimonio urbano informal con un patrimonio institucional (Estado de Chile y UNESCO). Las cifras develan que de las 219 animitas catastradas en la región de Valparaíso, 87 se sitúan en la ciudad de Valparaíso, 32 están presentes en la zona de conservación histórica, 5 se encuentran en el área histórica de la ciudad que fuera inscrita en el 2003 en la Lista del patrimonio mundial de la UNESCO, 5 están adheridas a un monumento histórico ${ }^{21}$ y 2 flanquean edificios que son objeto de conservación histórica (Ver Figura 4).

Es cierto que las animitas ignoran lo que clasifica o protege el Consejo Nacional de Monumentos, asimismo ignoran las políticas oficiales de construcción, y las normas oficiales de la Iglesia; pero estas omisiones no se asocian a un determinado tipo de reivindicaciones laicas y/o políticas, simplemente se debe al hecho que en Chile, la forma natural de conmemorar la muerte trágica ocurrida en el espacio público es construyendo una animita, y esta tradición sobrepasa todo código, norma o ley (Ver Figura 5).

Las animitas se emplazan en todos los sectores de las ciudades, ignorando las barreras socio-urbanas o las clasificaciones patrimoniales; sin embargo existe un mayor número de animitas en los sectores populares, lo que es atribuible a políticas nihilistas de ocultación practicadas por los sectores dominantes, puesto que, en Chile, es la Ley Orgánica Constitu- 


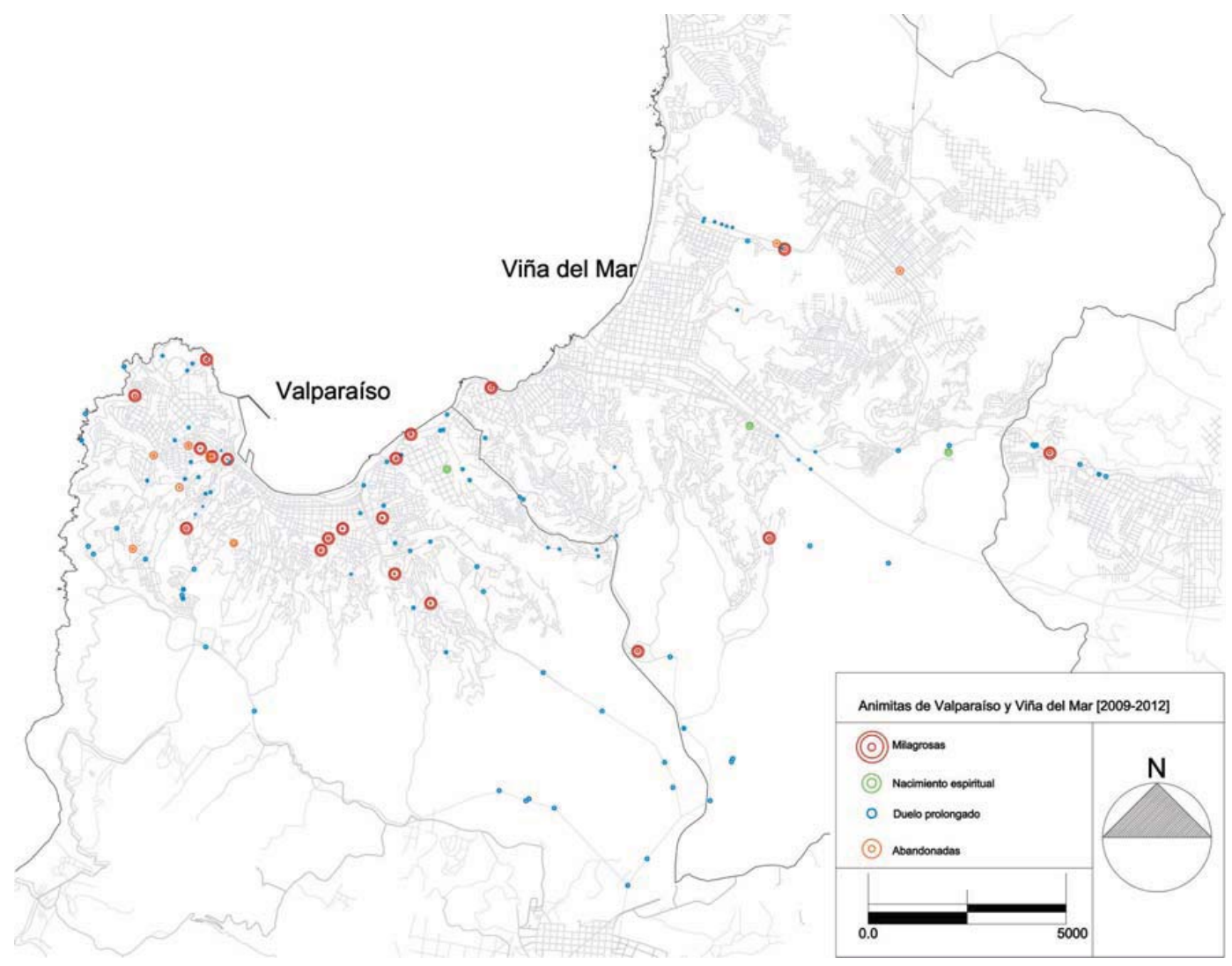

Figura 4 Cartografía georeferencial de animitas de las ciudades de Valparaíso y Viña del Mar. Fuente: Lautaro Ojeda, Tesis doctoral Territoires, architectures et pratiques issus d'une croyance seculaire: l'exemple des animitas du Chili, MECESUP Meta 28 y Universidad de Valparaíso

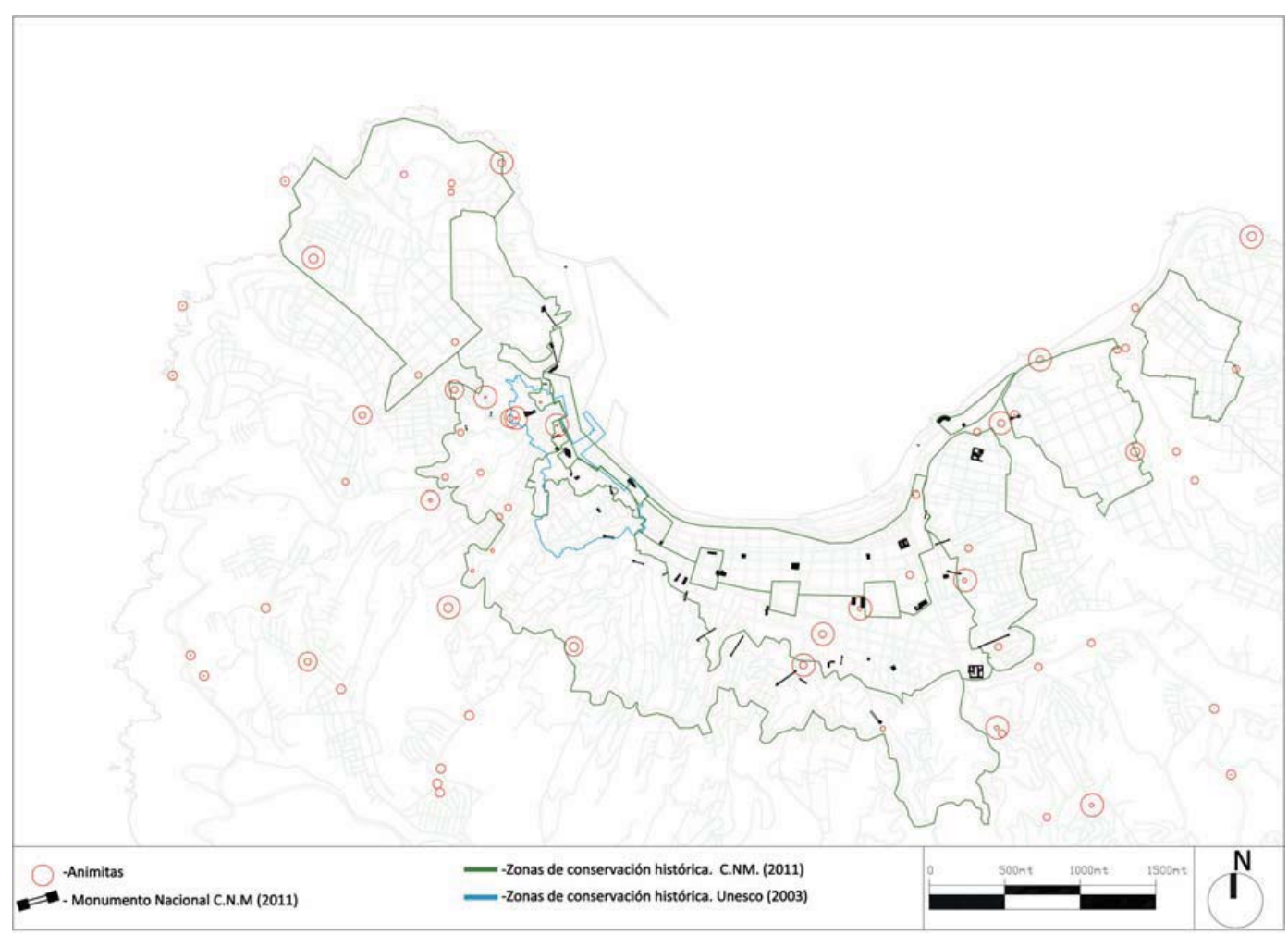

Figura 5 Planimetría de animitas en sector patrimonial de Valparaíso. Fuente: Lautaro Ojeda, Tesis doctoral Territoires, architectures et pratiques issus d'une croyance seculaire: l'exemple des animitas du Chili, MECESUP Meta 28 y Universidad de Valparaíso 
cional de Municipalidades (L.O.C.M) designa a los municipios como garantes del espacio público. Los que están en la obligación de velar su mantención y al cumplimiento de las reglamentaciones, es por eso que cada municipio puede determinar la presencia o la erradicación de las animitas presentes en sus jurisdicciones. Es también la razón para la cual existen varios casos de animitas donde las autoridades comunales destruyeron animitas al día que siguiente de su construcción, ya que algunas de estas autoridades consideran las animitas como idolatrías supersticiosas que molestan, representando una marca de primitivismo que perjudica la imagen de progreso que la clase dominante pretende alcanzar. Un ejemplo paradigmático de ello es el contraste que existe entre los municipios de Viña del Mar y de Valparaíso (ciudades contiguas). En Viña del Mar, contabilizamos solamente 30 animitas, de las cuales, cuatro son milagrosas (la mayoría en los sectores populares de la ciudad en cuestión), mientras que en Valparaíso contabilizamos 87 , de las cuales 14 son milagrosas. Lo cierto es que no hemos observado que en Valparaíso se destruyan animitas presentes en sectores gentrificados y/o sujetos a conservación histórica (Ver Figura 6).

Encontramos un caso paradigmático con el Departamento de Aseo y Ornato de la llustre Municipalidad de Valparaíso, donde se encuentra una animita que bloquea el paso fluido del acceso a sus dependencias, pero que, contradictoriamente, es cuidada por los mismos funcionarios municipales (Ver Figura 7).

Otro caso de este patrimonio de interferencia sustentado en una contra-memoria colectiva que actúa como complemento a la memoria oficial puede observarse en el barrio puerto, área histórica. Es el caso de la animita colectiva de Aldo Ayala Pozo, Avelina Pozo Muñoz, Ivonne Castro González y Eliseo Páez León, construida en el año 2007 a raíz de la explosión por gas de uno de los edificios de la calle Serrano y que significara el falleci-

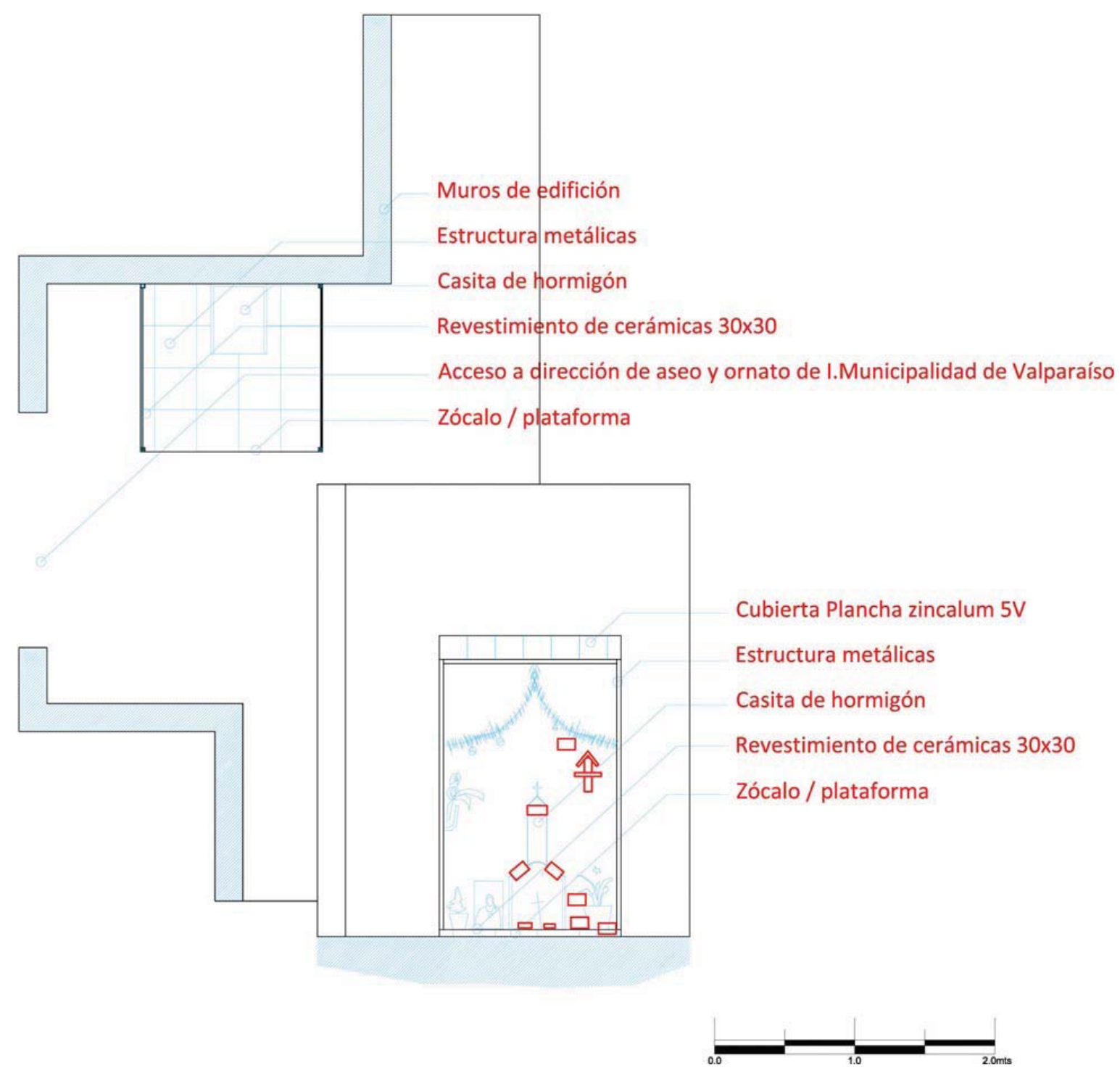

Figura 6 Planimetría de animita de Johnny ubicada en el acceso del Depto. de Aseo y Ornato de la I. Municipalidad de Valparaíso. Fuente: Lautaro Ojeda, Tesis doctoral Territoires, architectures et pratiques issus d'une croyance seculaire: l'exemple des animitas du Chili, MECESUP Meta 28 y Universidad de Valparaíso 
miento de las cuatro personas mencionadas, pues la animita se encuentra a algunos metros del memorial que el Municipio dispusiera en el año 2009 en honor a las víctimas de la tragedia, los familiares participaron del acto y agradecieron formalmente el gesto de las autoridades, lo interesante es la complementación de los dos memoriales y la mantención y cuidado en ambos durante el proceso de reconstrucción de la calle Serrano, a pesar de lo que podría haber dictado el proyecto de renovación urbana.

No debe conservarse, y tampoco hay jerarquías inmutables, pero la herencia urbana merece ser considerada. Toda la ciudad es histórica, toda la ciudad es dinámica, todos los elementos de la ciudad heredada son susceptibles de permanecer o desaparecer, casi ninguno es sagrado. Hay que explicitar primero los valores y luego los objetivos urbanísticos. $Y$ a partir de aquí evaluar las posibles opciones y sus impactos, para luego tomar las decisiones bien justificadas. (Borja, 2003: 41).

La ciudad contemporánea, y en este caso la ciudad de Valparaíso, en el afán de sumarse a este mercado patrimonial, tiende a definir un "centro histórico" y una serie de monumentos históricos, que en términos conceptuales pretenden centralizar la identidad del cuerpo social que habita toda la ciudad. A su vez, este centro con la confluencia de sus monumentos históricos definen una periferia que crece cada vez más rápido, hasta convertirse en metápolis (Ascher, 1995) o megápolis (Koolhaas, 2011). La contradicción de estas políticas urbanas y patrimoniales radican en que estos centros, al ser puntos de atracción turística y económica, tienen que mantener una imagen del pasado y a la vez estar en constante renovación, exhibiendo dinamismo y modernidad, lo cual dista enormemente de las dinámicas existentes en el centro histórico de la ciudad de Valparaíso, dinámicas que sufren de este afán mercantil del patrimonio ${ }^{22}$.

\section{CONCLUSIÓN}

Las animitas son formas abiertas de carácter orgánico que interactúan con la memoria viva del colectivo social que la practica, y son vehiculadas en espacios incrementales construidos colectivamente. Son espacios y lugares de carácter incremental y de geometría variable, también son una expresión material e inmaterial que vehicula un capital cultural, que gracias a sus formas de apropiaciones informales crean un soporte de construcción cultural, colectiva y urbana, que otorga sentido y cualidad a nuestras ciudades. Es así como en esta práctica, inmaterialidad y materialidad son indisociables, y se presentan como una lección de las manifestaciones urbanas del derecho a la ciudad, que en el caso de Valparaíso se plasman sobre las zonas de conservación histórica estableciendo una dialéctica entre dos tipos de patrimonios. Es de esta forma que Las animitas en tanto patrimonio de interferencia se presentan como unos verdaderos palimpsestos urbanos que se rehacen, se desdibujan, se reconstruyen y se destruyen, interfiriendo con los espacios planificados y/o protegidos.

\section{Vue frontal avant explosion}
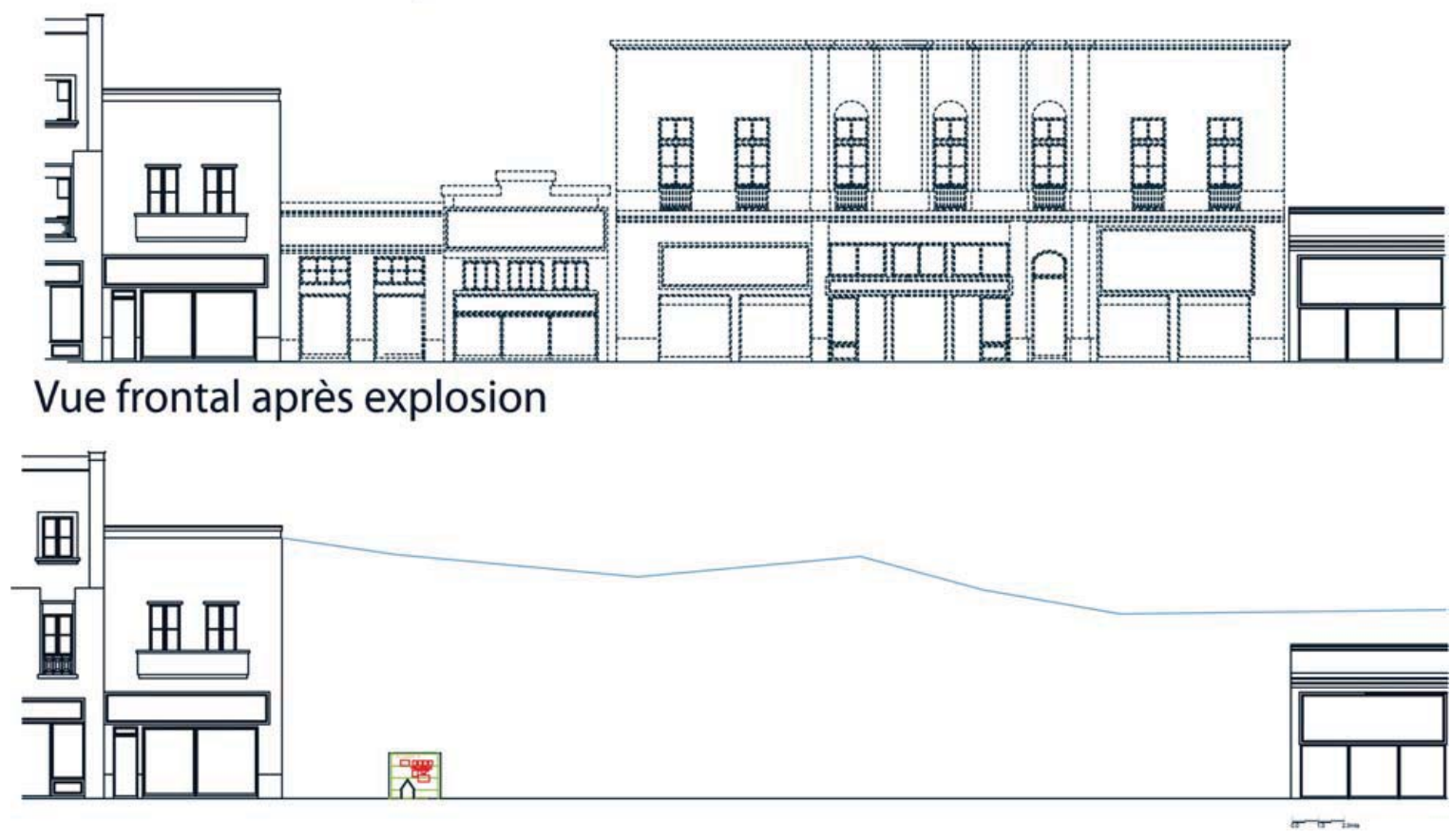

Figura 7 Elevación frontal de animita de Avelina Pozo. Fuente: Lautaro Ojeda, Tesis doctoral Territoires, architectures et pratiques issus d'une croyance seculaire: l'exemple des animitas du Chili, MECESUP Meta 28 y Universidad de Valparaíso 
Concluimos que las animitas urbanas son un patrimonio urbano de interferencia de escala menor, y quienes las han fabricado y siguen fabricándolas constituyen la base de una ciudad oculta, informal y desvalorada, que como un mosaico urbano codificado se ha establecido de forma paralela al modelo formal de nuestras ciudades, construyendo una contra-memoria colectiva vehiculada en múltiples memoriales que interfieren con el espacio urbano. $Y$ resulta indispensable que estas, al igual que las otras prácticas informales, no sean descalificadas o destruidas por las políticas de mercado patrimonial o capitalista.

\section{NOTAS}

1. Proyecto Fondart Regional Animitas en el camino, $N^{\circ} 19189-$ 2 y Universidad de Valparaíso MECESUP meta 28.

2. Animitas de Autopista Central y Animitas de CONASET: en el año 2004 en el proceso de construcción de la Autopista Central se tenía que ampliar la faja fiscal de la antigua Carretera Panamericana, por lo que la concesionaria, al verse enfrentada al destino de las animitas pre-existentes, decidió desplazarlas y estandarizarlas. En el año 2011 la Comisión Nacional de Seguridad de Tránsito (CONASET), lanzó la campaña "Manéjate por la vida"3, la cual tenía como principal objetivo ampliar la alerta y cautela de los automovilistas y peatones con respecto a los accidentes de tránsito. La campaña se estructuró con una intervención urbana en Santiago disponiendo 500 animitas estándares.

4. Hemos realizados 2 prospecciones en el norte grande de Chile y Sur del Perú, una financiada por MECESUP por una beca doctoral, y el segundo financiado por el Institut des Amérique de l'Université de Rennes 2, Bretagne France.

5. Animita como objeto holográfico: Las animitas tienen un sinfín de formalizaciones, y analizando el registro que poseemos hemos detectado 8 arquetipos, Ellos son: las casas tradicionales, las iglesias, las grutas, las orgánicas, las cruces, las casas modernas, las socio-institucionales, y las híbridas (Ojeda, 2011: 81).

6. Animita como sujeto holográfico: La primera noción que los practicantes poseen con respecto a las animitas es que estas son las almas de los que han muerto de forma trágica en la vía pública [...] la animita entendida como sujeto tiene un carácter holográfico en cuanto no posee una identidad e historia única, puesto que esta se construye y desconstruye gracias al imaginario devocional que los practicantes vehiculan de diversas formas (Ojeda, 2011: 79).

7. Animita como lugar holográfico: El carácter holográfico de la animita como lugar queda de manifiesto cuando estas sobrepasan su tamaño fundacional, y se desdibuja el pequeño edículo en una compleja superposición de ofrendas y objetos de acomodo (bancas, sillas). Hemos subdividido esta variación formal en cinco categorías, las cuales están estrechamente ligadas al fervor devocional que la animita recibe (Ojeda, 2011: 83), es lo que hemos definido como etapas espirituales, estas son: construcción espiritual, duelo prolongado, nacimiento espiritual, santificación espiritual (animita milagrosa) y muerte $\mathrm{y} / \mathrm{o}$ abandono.
8. En 1971 se declaró como Zona Típica al pueblo de La Tirana en el norte de Chile, pueblo donde se desarrollan bailes religiosos sincréticos de carácter popular. Es el primer reconocimiento a una práctica de origen popular, pues entre 1925 y 1971 se habían declarado 73 monumentos, todos monumentos históricos de connotación militar, religiosa o pública.

9. 1969, Casa donde nació Gabriela Mistral, Coquimbo, Elqui, Vicuña (MH). 1979, Casa escuela rural de Monte Grande donde vivió y estudió Gabriela Mistral, Coquimbo, Elqui, Paiguano (MH). 1990, Casa que fuera de Gabriela Mistral, Coquimbo, Elqui, La Serena (MH). 1990, Casa de Pablo Neruda, Valparaíso, San Antonio, El Quisco (MH). 1990, Casa de Pablo Neruda, La Chascona, Metropolitana de Santiago, Santiago, Providencia (MH). 1992, Casa donde nació Violeta Parra, Biobío, Nuble, San Carlos (MH). 2008, Casa de Gabriela Mistral, Coquimbo, Elqui, La Serena (MH). 2011, Casa Museo La Sebastiana, Valparaíso, Valparaíso, Valparaíso (MH).

10. Sector patrimonial de Valparaíso: Sector iglesia de La Matriz y Plazuela Santo Domingo, Sector Plaza Echaurren, calle Serrano y entorno, Sector Muelle Prat, Plazas Sotomayor y Justicia y Museo del Mar, Sector calle Prat, Plazuela Turri y entorno, Sector de los Cerros Alegre y Concepción.

11. Bienes patrimoniales de Chile inscritos en la Lista de patrimonio mundial de la UNESCO: 2000, Iglesias de Chiloé; 2003, Casco histórico de la ciudad de Valparaíso; 2006, Ciudad minera de Sewel; 2005, Salitreras de Humberstone. Fuente: Consejo Nacional de Monumentos 2012.

12. Fuente: Consejo Nacional de Monumentos 2012.

13. Animitas de Fusilados: Serafín Rodríguez, Valdivia (1906); Luis Amadeo Brihier Lacroix, Valparaíso (1907); Francisco Manríquez, Talca (1933); Emilio Inostroza Sepúlveda, Temuco (1941); José René Ferrada y Federico Mardones, Lautaro (1949); Francisco Cuadra y Luis Osorio Santiago (1963); Jorge del Carmen Valenzuela Torres, San Carlos (1963).

14. Animitas víctimas de la dictadura: 1981 los dinamitados (Calama), 1982 Tucapel Jiménez (Lampa), 1983 Juanita Guajardo (Antofagasta), 1985 los hermanos Rafael y Eduardo Vergara Toledo (Villa Francia, Santiago) y en 1984 los Carabineros Hugo Armando Toledo Trejo, Ángel Sazo CastiIlo , Uldaricio Aravena Sanhueza, Patricio Eduardo Delgado Vergara (subida Santos Ossa).

15. Ciudad Histórica: La ciudad "histórica" está en nuestro imaginario, y también en la realidad física y funcional de la ciudad actual. El desafío hoy es saber encontrar su rol funcional y simbólico en el nuevo territorio urbano, que como dijimos va más allá de la ciudad metropolitana producida por la sociedad industrial (Borja, 2003, p. 41).

16. Patrimonio Urbano y Gustavo Giovannoni: Françoise Choay (1992) plantea que fue Giovannoni quién invento dicha noción tras asimilar y mejorar las posturas de John Ruskin y Camillo Sitte.

17. Zonas típicas de Valparaíso declaradas por el Consejo de Monumentos: 1971: Entorno Iglesia La Matriz, Valparaíso, Entorno a Monumento Histórico. 1976: Plaza Aníbal Pinto, Valparaíso, Área Urbana. 1979: Plaza Sotomayor, Valparaíso, Área Urbana. 1979: Cerros Alegre y Concepción, Valparaíso, 
Área Urbana. 1986: Complejo ferroviario de la Estación Barón, Valparaíso, Entorno a Monumento Histórico. 1994: Sector Pasaje Ross, Valparaíso, Área Urbana. 2001: Sector Quebrada Márquez, Valparaíso, Área Urbana. 2001: Sector Plaza Echaurren y calle Serrano, Valparaíso, Área Urbana. 2001: Sector Cerro Cordillera, Valparaíso, Área Urbana. 2001: Sector Bancario de Calle Prat, Valparaíso, Área Urbana. 2001: Área Histórica de Valparaíso, Valparaíso, Área Urbana.

18. Área Histórica de Valparaíso patrimonio mundial UNESCO 2003: 1. Sector iglesia de La Matriz y Plazuela Santo Domingo (1971), 2. Sector Plaza Echaurren (2001), 3. Calle Serrano y entorno (2001), 4. Sector Muelle Prat, Plazas Sotomayor y Justicia y Museo del Mar, 5. Sector calle Prat, plazuela Turri y entorno (2001), 6. Sector de los cerros Alegre y Concepción (1979).

19. En 2003, el Comité del Patrimonio mundial declaró lo siguiente:

1. Inscribir el barrio histórico de la ciudad portuaria de Valparaíso, Chile, en la Lista del patrimonio mundial bajo el criterio cultural (iii): Criterio iii: Valparaíso constituye un testimonio excepcional de la primera fase de globalización del final del siglo XIX, cuando se volvió el primer puerto comercial de las vías marítimas de la costa pacífica de Sudamérica.

2. Fomenta al Estado parte que debe proseguir sus esfuerzos para elaborar el inventario y garantizar la protección de las infraestructuras vinculadas a las funciones históricas de la zona portuaria y los sistemas de transporte.

3. Fomenta al Estado parte para elaborar planes de gestión de conservación para el conjunto de la zona portuaria marítima. Solicita al Estado parte de precisar las normas y las orientaciones que deben cumplirse en los barrios que lindan las zonas protegidas, por ejemplo. Plaza de la Intendencia, Cementerio, y Plaza San Francisco.

20. Instituciones implicadas: Consejo de Monumentos Nacionales, Ilustre Municipalidad de Valparaíso, MINVU V región, P.D.G.P Valparaíso (Plan Director de Gestión Patrimonial de Valparaíso) y el P.R.D.U.V (Programa de Recuperación y Desarrollo Urbano de Valparaíso).

21. Paisajes de interferencia: Los paisajes de interferencia se refieren a las manifestaciones de la ciudad oculta que están dentro de la ciudad formal y no constituyen asentamientos aparte, al margen; son tangentes a los barrios formales y se mantienen como aquello que difiere y no es lo mismo, sea por su constitución física o social (Tardin Coelho, 2007:207)

22. Se trata de la animita de Rigoberto Mura que está adosada la Torre Reloj de la Estación Barón de Ferrocarriles de Valparaíso (Monumento Histórico desde 1972); la animita de Colón (cerca de un edificio de conservación histórica); la animita colectiva de Aldo Ayala Pozo; Avelina Pozo Muñoz; Ivonne Castro González y Eliseo Páez León. (adherida a un edificio protegido de la zona histórica); animita de Rosita (contexto idéntico); animita de Manolito (adosada a la escuela Ramón Barros Luco, un monumento histórico desde 2003); animita sin nombre de la calle Hermanos Clark (a metros del ascensor Larraín, Monumento Histórico desde 1998); animita de Johnny Frías (cerca del ascensor La Cruz, monumento histórico), la mayoría de estos casos se en- cuentran en la zona patrimonial inscrita en la Lista de patrimonio mundial de la UNESCO en el 2003.

23. En el área histórica, han desaparecido todos los emporios, que eran los almacenes típicos de la zona y han sido reemplazados por farmacias.

\section{BIBLIOGRAFÍA}

Arizpe, Lourdes (2006). Los debates internacionales en torno al patrimonio cultural inmaterial. Cuicuilco, 38, pp. 13-27.

Arriaza, Bernardo (2003). Cultura Chinchorro, las momias artificiales más antiguas del mundo. Santiago: Editorial Universitaria.

Ascher, François (1995). Métapolis ou L'avenir des villes. Paris: Odile Jacob. - (2004). Los nuevos principios del urbanismo Madrid: Alianza editorial.

Augé, Marc (1992). NON-LIEUX, introduction à une anthropologie de la surmodernité Paris, édition du SEUIL.

Ayala Rocabado, Patricia (2007-2008). Memorialización estatal del pasado indígena y las políticas de la memoria atacameña. Revista chilena de antropología, 19, pp. 37-62.

Bialogorski, Mirta (2002). Una aproximación crítica a la dicotomía tangible/intangible en el abordaje del patrimonio cultural desde las nuevas perspectivas del folclore. Cuadernos, Revista de la Facultad de Humanidades y Ciencias Sociales, 18, pp. 241-248.

Bojalil, Sergio (2002). Patrimonio ciudadano. Reencuentro, 35, pp. 92-97. Borja, Jordi. (2003). La ciudad conquistada. Madrid: Alianza.

(2007). Revolución y contrarrevolución en la ciudad global: las expectativas frustradas por la globalización de nuestras ciudades. Revista EURE. vol.33, número 100, pp. 33-50.

(2011). Espacio público y derecho a la ciudad. En Institut de Drets Humans de Catalunya, el derecho a la Ciudad, pp. 139-164. Barcelona, 2011.

Choay, Françoise \& Merlin, Pierre (2010). Dictionnaire de l'urbanisme et de l'aménagement. Paris: Puf.

Choay, Françoise (1992). L'allégorie du patrimoine. Paris: Le Seuil. (2006). Pour une anthropologie de l'espace. Paris: édition du SEUIL. (2009). Le patrimoine en questions: anthologie pour un combat. Paris: édition du SEUIL.

(2011). La terre qui meurt. Paris: Fayard.

Curtoni, Rafael Pedro \& Chaparro, María Gabriela (2007-2008). El Reentierro del cacique José Gregorio Yancamil. Patrimonio; política y memoria de piedra en la pampa Argentina. Revista Chilena de antropología, Vol. 19, pp. 9-36.

García-Canclini, Néstor (2009), Culturas Híbridas, estrategias para entrar y salir de la modernidad. Ciudad de México: De bolsillo.

(2005), La antropologia Urbana en México, Ciudad de México: Fondo de Cultura Económica, Consejo Nacional de la Cultura y las Artes y Universidad Autonomoa Metropolitana.

Girault, Louis (1988). Rituales en las regiones andinas de Bolivia y Perú. La Paz: Don Bosco. 
Gobierno de Chile (2004). Postulación de Valparaíso como sitio del patrimonio mundial UNESCO. Cuadernos del Consejo de Monumentos Nacionales, segunda serie № 70 . Santiago: Consejo de Monumentos Nacionales.

González Virós, Itziar (2007). La percepción y el trazado del territorio latente, la construccion social del paisaje. En Nogué, J.(Ed), la construcción social del paisaje (pp. 163-179). Madrid: editorial biblioteca nueva.

Koolhaas, Rem y Mau, Bruce (1995). Small, medium, large, extra-large, Office for Metropolitan Architecture, New York: Monacelli Press.

Koolhaas, Rem [2001] (2011). Junkspace. Paris: Payot \& Rivage.

Lacarrieu, Mónica (2004). El patrimonio cultural inmaterial: un recurso político en el espacio de la cultura pública local. Actas del VI seminario sobre patrimonio cultural: instantáneas locales, Santiago: Dibam, pp. 154-180.

(2007). La insoportable levedad de lo urbano. Revista EURE. Vol. 33, número 099, pp. 47-64.

Ley General de Urbanismo y Construcción (L.G.U.C) (2010).

Ley Orgánica Constitucional de Municipalidades (L.0.C.M) (2002).

Lindón, Alicia (2000). La espacialidad como fuente de las innovaciones de la vida cotidiana. Hacia modos de vida cuasi fijos en el espacio. En Lindón, Alicia (Ed), La vida cotidiana y su espacio-temporalidad (pp. 187-210). Barcelona: Anthropos Editorial.

(2007). La construcción social de los paisajes invisibles del miedo. En Nogué, Joan (Ed), La construcción social del paisaje (pp. 217240). Madrid: Editorial biblioteca nueva.

(2007). Los imaginarios urbanos y el constructivismo geográfico: Ios hologramas espaciales. Revista EURE, 99, pp. 31-46.

Lira Latuz, Claudia (1999). La animita en el ámbito del arte. revista AISTHESIS 32, pp. 74-97.

(2002). El rumor de las casitas vacías, estética de la animita. Santiago: LOM ediciones.

(2009). La animita: historia y diseño. Revista 180, 23, pp. 20-23.

López, Loreto (2004). Algunas consideraciones sobre el patrimonio cultural inmaterial: un recurso político en el espacio de la cultura pública local. Actas del VI seminario sobre patrimonio cultural: instantáneas locales, Santiago: Dibam, pp. 183-187.

Losonczy, Anne-Marie (2001). Santificación popular de los muertos en cementerios. Revista Colombiana de Antropología, n 37, pp. 6-23.

Massó Guijarro, Ester (2006). La identidad cultural como patrimonio inmaterial: relaciones dialécticas con el desarrollo. Theoria Universidad del Bío-Bío, 15, pp. 88-99.

Morin, Edgar (2003). El hombre y la muerte. Editorial Kairós. ( $4^{\text {ta }}$ ed.), (1 ${ }^{\mathrm{a}}$ edición francesa, L'HOMME ET LA MORT. Paris, édition du SEUIL, 1970).

Ojeda, Lautaro (2011). HOLOGRAMAS DE LA MUERTE IMPREVISTA: pregnancia urbana de las Animitas en Chile. Geograficando, № 7 , pp. $68-89$.

Ojeda, Lautaro y Torres, Miguel (2011). Animitas, deseos cristalizados de un duelo inacabado. Consejo Nacional de la Cultura y las Artes, Santiago: LOM ediciones.

Ordenanza General de Urbanismo y Construccion (0.G.U.C). (2010)
Parker, Cristián (1992). Animitas, machis y santiguadoras en Chile: creencias religiosas y cultura popular en el Bío Bío: un proceso de investigación-acción a partir de la acción social de la Iglesia en Concepción y Arauco. Santiago: Ediciones Rehue.

(1996). Otra lógica para América Latina, religión popular y modernización capitalista. Santiago: Fondo de Cultura Económica.

Plath, Oreste. (1995). L'animita: hagiografía folclórica. Santiago, P \& P Editorial.

Rojas Farías, Víctor (2001). Valparaíso, el mito y sus leyendas. Santiago: Ril Editores.

Salas Astrain, Ricardo (1992). Violencia y muerte en el mundo popular. Reflexiones en torno al simbolismo de las "ánimas". Estudios sobre las Culturas Contemporáneas, 13-14, pp. 181-192.

Tardin Coelho, Raquel. (2007). Los paisajes de la ciudad oculta. En Nogué, J. (Ed), La construcción social del paisaje. pp. 163-179. Madrid: Editorial Biblioteca Nueva.

UNESCO (1972). Convención sobre la protección del patrimonio mundial, cultural y natural. PARIS: Naciones Unidas para la Educación, la Ciencia y la Cultura.

(2010). Textos fundamentales de la Convención para la Salvaguardia del Patrimonio Cultural Inmaterial de 2003. PARIS: Naciones Unidas para la Educación, la Ciencia y la Cultura. 